Part of Journal of Research of the National Bureau of Standards, Volume 18, April 1937

\title{
PRECISION CAMERA FOR TESTING LENSES
}

\author{
By Irvine C. Gardner and Frank A. Case
}

\begin{abstract}
Apparatus particularly adapted to the testing of airplane camera lenses and complete airplane cameras is described. Seven collimators provide optically distant targets spaced five degrees. These targets are photographed by means of the lens or camera to be tested. An examination and measurement of the resulting negative gives the back focal length, equivalent focal length, and both distortion and quality of definition over the entire field of the lens. This instrument was designed and built for making the tests that are required by all contracts for Government mapping projects.
\end{abstract}

\section{CONTENTS}

II. Principles of

III. Mechanical design

IV. Test charts _... 453

V. Adjustment of instrument...... 455

VI. Operation of lens-testing camera

VII. Photographic technique

VIII. Interpretation of test negatives_...

\section{INTRODUCTION}

Shortly after the close of the World War the National Bureau of Standards began testing camera objectives for the U. S. Army Air Corps in order to determine their suitability for use in airplane cameras for mapping projects. The measurements made included determinations of spherical aberration, chromatic aberration, curvature of field, astigmatic difference, and distortion. With the advent of the multiple-lens camera and the increasing utilization of airplane photographs for the construction of topographic maps, the importance of good definition and relative freedom from distortion has become so generally recognized that lenses are seldom installed in airplane cameras without prior measurements of the distortion. The first large lot of airplane lenses received by this Bureau was tested on a bench improvised from parts that were immediately available. A report of these measurements and a description of the apparatus employed have been given by Bennett. ${ }^{1}$ When it became evident that airplane camera lenses were to be regularly forwarded to the Bureau for test, a special optical bench adapted to this work was constructed, and this apparatus has also been described. ${ }^{2}$ For the measurement of

\footnotetext{
1 BS Sci. Pap. 19, 587 (1924) S494.

2 J. Opt. Soc. Am. \& Rev. Sci. Instr. 14, 235( 1927).
} 
the focal length and distortion this bench has proved entirely satisfactory. It is, however, difficult to formulate precise statements regarding the quality of definition of a lens after a bench test has been made, and it is also difficult to determine the value of the back focal length which gives the best average definition over all parts of the field as distinguished from that which gives the best definition on the axis. The precision camera for testing lenses, to be described, was designed and constructed to meet these difficulties and also to expedite the testing of the increasingly large number of airplane camera lenses which is regularly received each year. Not only does this camera
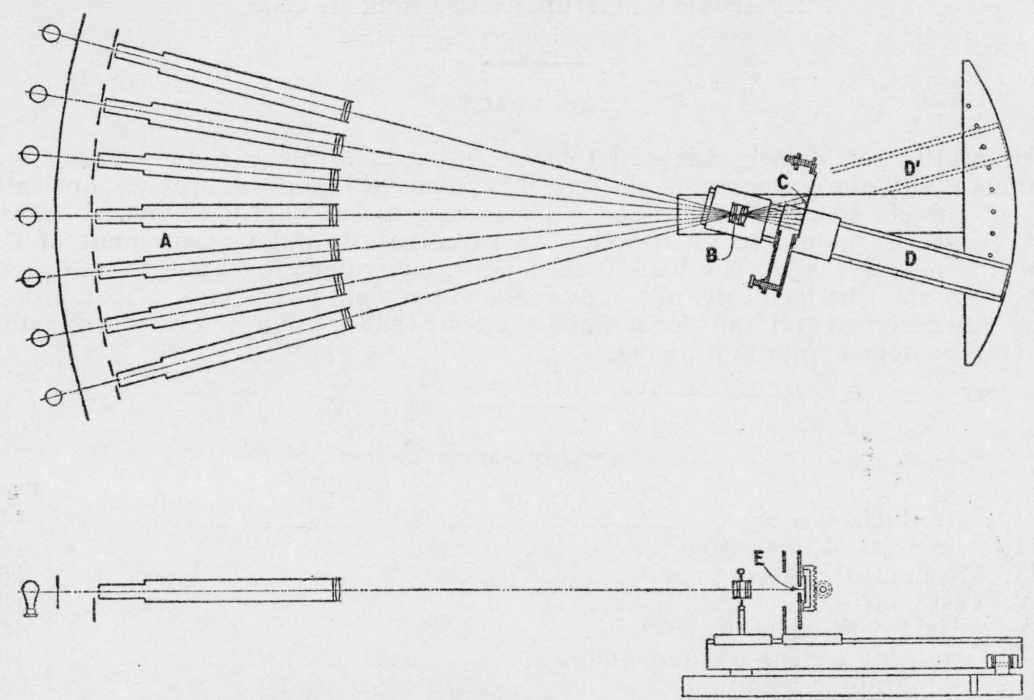

FIGURE 1.-Schematic representation of the precision camera.

The seven collimators are at the left, the lens to be tested at $B$, and the photographic plate at $C$.

permit the tests to be made with less expenditure of time and effort, but its use has the further advantage that the negative, made with each lens, constitutes a precise record of the performance of the lens and one which may be preserved for future reference. This apparatus also permits tests to be made on a complete single lens camera with the lens assembled in the camera as it will be when used.

\section{PRINCIPLES OF OPERATION}

The fundamental elements of the precision camera are shown schematically in plan and in elevation in figure 1. At $A$ is a battery of seven collimators, each of which carries a test chart located in the focal plane of its objective and illuminated by transmitted light. The axes of the collimators intersect at $B$, and the angle between any two successive collimators is nominally $5^{\circ}$. The lens to be tested is located at $B$, where it receives light from the seven infinitely distant images as optically presented by the battery of collimators. The images produced by the objective under test are received on the photographic plate at $C$. The lens at $B$ and the plate at $C$ are carried by a common structure which forms the camera proper. This camera 
is rotatable about a point beneath the lens and may be brought into any one of several positions including those indicated as $D$ and $D^{\prime}$. When in the position $D$ images are recorded on the photographic plate at $0,5,10,15,20,25$, and $30^{\circ}$ from the axis and for position $D^{\prime}$ the same is true, except that the images lie on the other side of the axis. Provision is also made for rotating the camera $5^{\circ}$ beyond each of the extreme positions shown. This permits the performance of a lens to be tested for a point $35^{\circ}$ from the axis. The light reaches the photographic plate through the slot at $E$, and a mechanism is provided for lowering or raising the plate to permit a series of exposures to be made on a single plate. There is also a slow motion by which the photographic plate may be moved toward or away from the lens through precisely measured distances.

In practice, 19 exposures may be made on a single plate ( 4 by 10 inches), each one being made with the plate at a different distance from the rear vertex of the lens. The arrangement of the images on the resulting negative is shown in figure 2. All the images in a given vertical column are at a given angular distance from the center

\begin{tabular}{|c|c|c|c|c|c|c|}
\hline $\begin{array}{l}\text { 品 } \\
\text { 品 } \\
\text { 品 } \\
\text { 品 } \\
\text { 品 } \\
\text { 品 } \\
\text { 品。 }\end{array}$ & 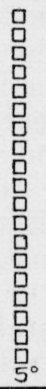 & 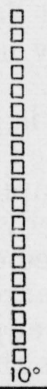 & $\begin{array}{l}\text { 品 } \\
\text { 品 } \\
\text { 品 } \\
\text { 品 } \\
\text { 品 } \\
\text { 品 } \\
\text { 品 } \\
\text { 品 }\end{array}$ & $\begin{array}{l}\text { 品 } \\
\text { 品 } \\
\text { 品 } \\
\text { 品 } \\
\text { 品 } \\
\text { 品 } \\
\text { 品 } \\
\text { 品 } \\
20^{\circ}\end{array}$ & 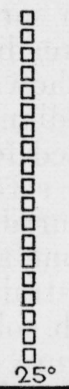 & 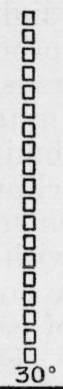 \\
\hline
\end{tabular}

FIGURE 2.-Schematic drawing of the negative obtained with the precision camera.

of the field as indicated by the values given on the figure. All of the images in any horizontal row are made by a single exposure and between any two such rows the plate has been withdrawn a definite distance from the lens. The general principle of operation and the arrangement of the images upon the negative is the same as described by Goldberg, ${ }^{3}$ although the mechanical construction is entirely different and the addition of the collimators permits lenses of longer focal length to be satisfactorily tested.

Each square represents the image from a collimator as recorded on the negative. The images in a given row are exposed simultaneously and show in the several columns the performance of the lens for each of the indicated angular distances from the center of the field. From exposure to exposure, the distance from the lens to the plate is altered by known amounts. Consequently, each row represents a different focal adjustment, and the one giving the best average definition may be selected as typical of the best performance of the lens.

3 Sixième Congres International de Photographie, p. 186-193 Paris (1925). 


\section{MECHANICAL DESIGN}

The details of design and construction are well shown in the photographic reproductions of figures 3,4 , and 5 . Figure 3 gives a general view of the entire apparatus. The seven collimators are clearly visible at $A$. The camera back at $C$ partially hides the chuck at $B$ which holds the lens to be tested. The photographic plate rests on two ledges of the aluminum casting carried by the camera back $C$. The ledges extend across the entire back and permit the placing of a plate 4 inches wide, for photographing any portion of the field of the lens, on either side of the axis, without adjustment other than the placing of the plate in the proper position on the two supporting ledges. With this arrangement for holding the plate the room must be darkened during the loading of the camera and it is preferable to keep it dark while the exposures are being made. A loosely fitting cover is provided in order to lessen the danger of stray light reaching the plate during the exposure.

The casting carrying the photographic plate is lowered to present fresh portions of the emulsion for successive exposures. The rack and pinion movement for effecting this is shown in figure 3 . On this mechanism an index plate and a spring-actuated detent are also provided to permit the plate to be readily shifted by uniform steps.

The battery of collimators is shown in figure 4. The free apertures of the collimators are $75 \mathrm{~mm}$ in diameter, which is greater than those of the lenses commonly submitted for test. Rack and pinion movements for focusing and locking screws for clamping the drawtubes when correct focus has been secured are provided. Each collimator is geometrically mounted with one support (three constraints) under the objective end and three constraints at the target end. The constraints at the target end of each collimator are adjustable to permit it to be aligned as desired. Figure 4 also shows the rotating sectors and the lamps which form the illuminating system for the test charts or targets in each collimator. This portion of the apparatus will be more fully described in section IV.

The camera proper, shown in figure 5 , consists of a bed provided with ways, three carriages, and a lead screw. Each carriage is provided with a half-nut, which is normally disengaged from the lead screw but which can be engaged when a slow motion is required for adjustment. Clamps are also provided by which any carriage can be locked in position. The first carriage, nearest the collimator, carries the chuck which receives the lens to be tested; the second carries the camera back; and the third carries a microscope for observing the image. This last carriage also has a vernier applied to the scale carried by the bed. The ways are $121 \mathrm{~cm}$ long and lenses with focal lengths lying between 15 and $95 \mathrm{~cm}$ can be accommodated.

The bed of the camera is mounted on a vertical spindle at the end nearer the collimators. This spindle is provided with annular and thrust ball bearings. The outer end of the camera bed is carried by two rollers which rotate on ball bearings. These rollers roll on the circular arc clearly visible in figure 3. This circular arc has index holes spaced nominally 5 degrees, and the camera bed carries a corresponding index pin. It is, therefore, possible to lock the camera, by means of this pin, not only in the extreme positions that have been particularly mentioned in section III but also in a series of intermediate positions 


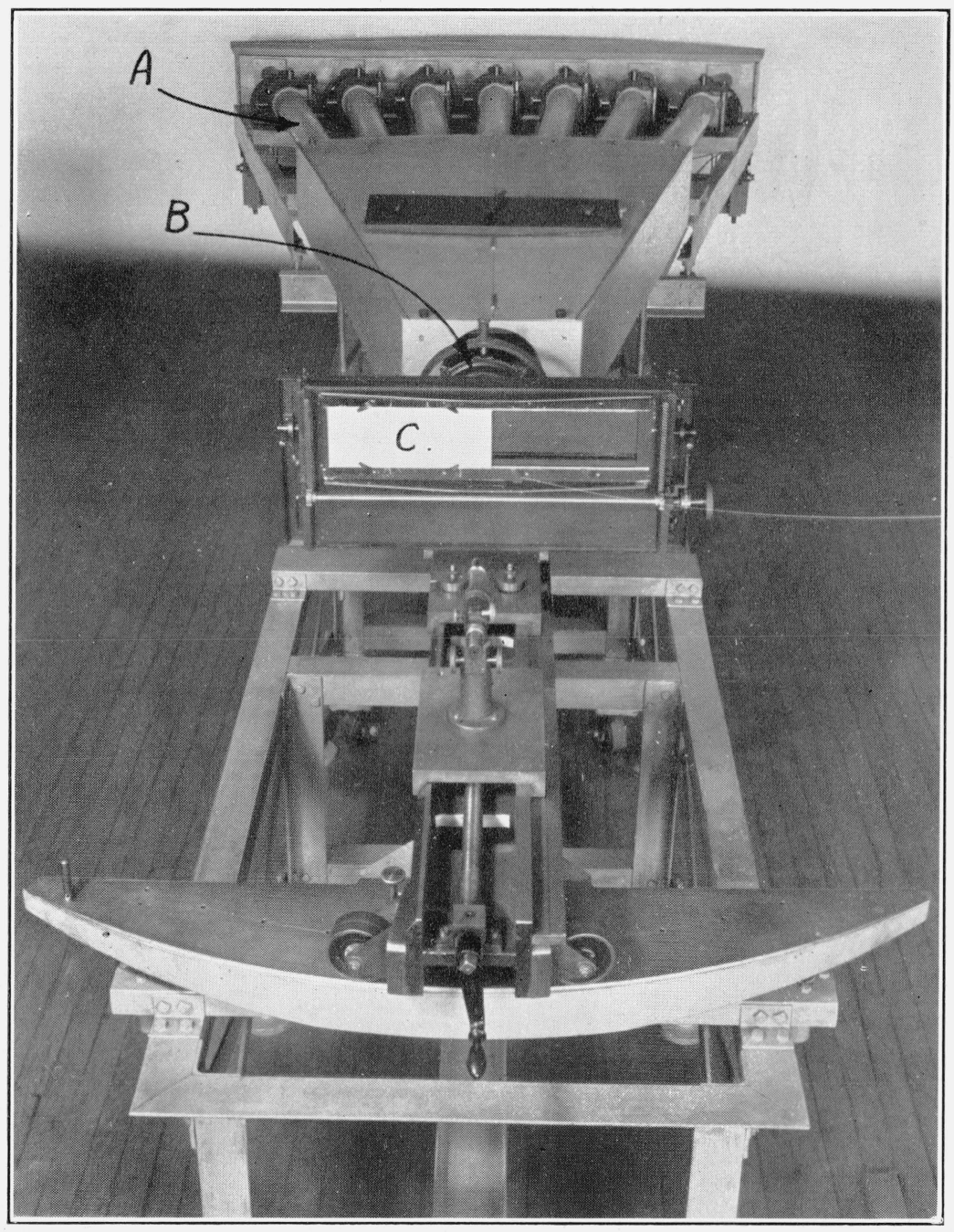

Figure 3.-Complete precision camera.

The collimators are at $A$, the lens to be tested at $B$, and the photographic plate at $C$. 


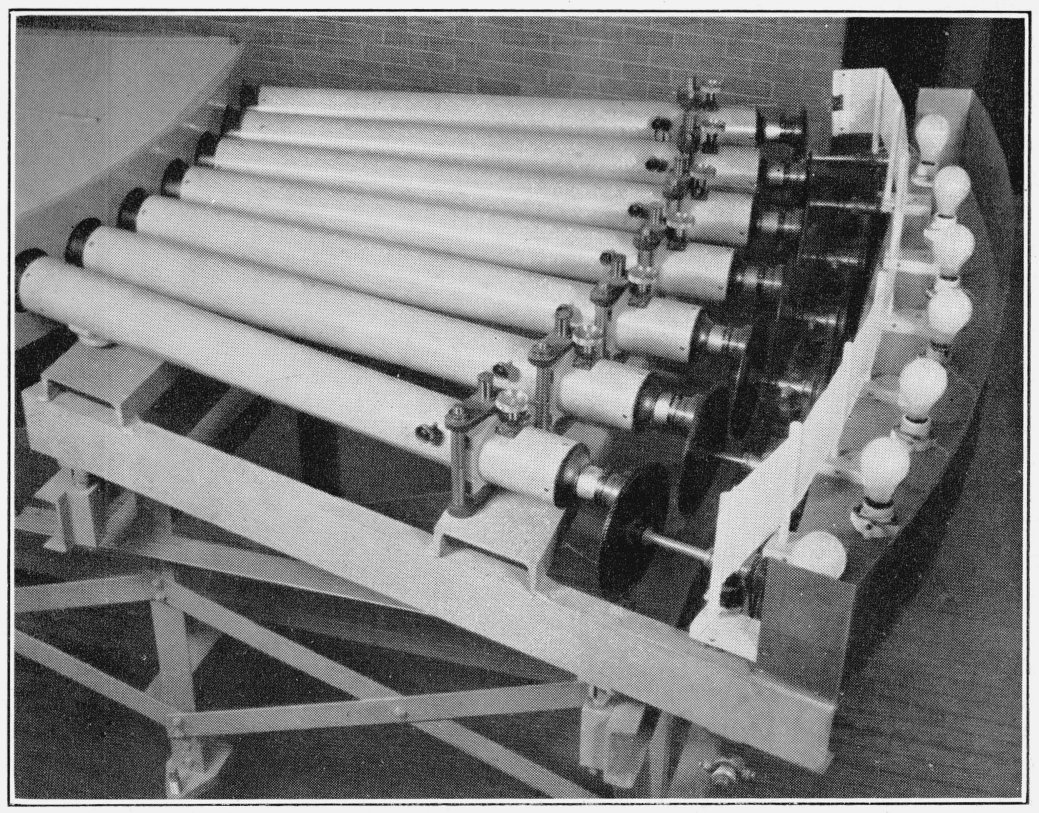

FIGURE 4.-Collimators, sources of light for illuminating the test charts, and sectored disks for balancing the vignetting of the lens at different angular distances from the center of the field.

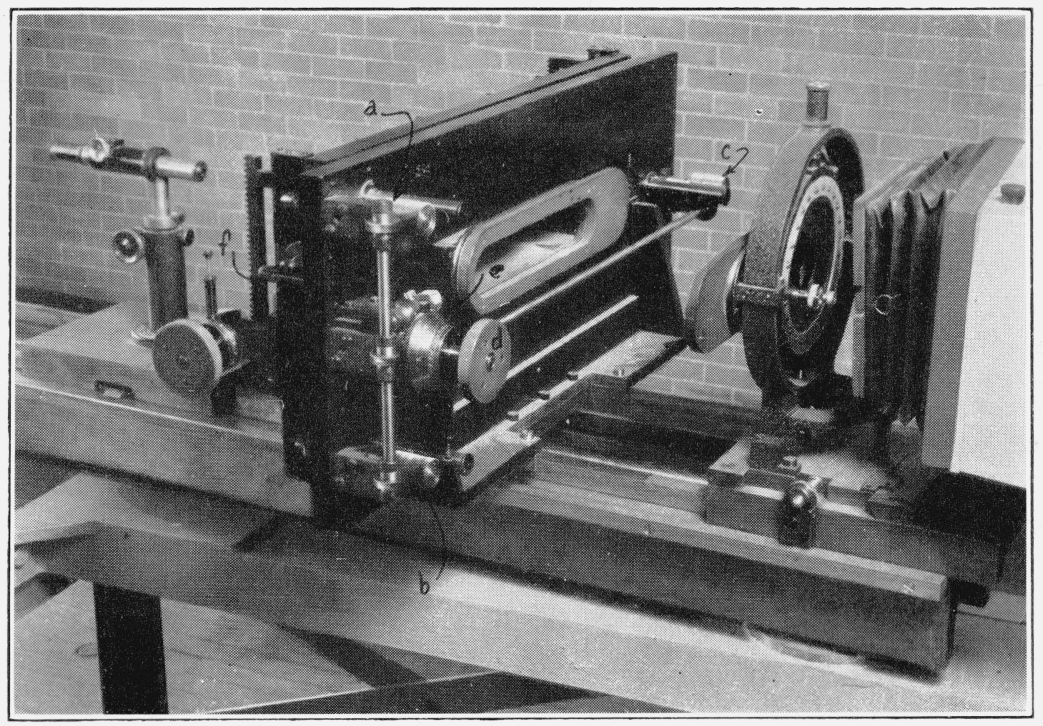

FigURE 5.-Lens mount and camera back.

The carriage at the right carries the chuck that holds the lens to be tested. The central carriage carries the camera back. The spiral gears that actuate the three micrometer screws for obtaining a fine focusing movement and one of the racks that lowers the plate between successive exposures are clearly shown. The third carriage carries a microscope for preliminary focusing. 
so that the axis of the camera can be brought into coincidence with the axis of any one of the seven collimators. These intermediate positions are used in adjusting and calibrating the instrument.

The chuck that receives the lens to be tested, shown at the right of figure 5 , is mounted to permit translation along or rotation about each of three mutually perpendicular axes, thereby permitting the lens to be centered and adjusted with its axis normal to the photographic plate. The camera back mounted on the center carriage shown in figure 5 consists of two parts. The main part or supporting member is mounted rigidly upon its carriage and carries three micrometer screws at $a, b$, and $c$, respectively, which serve to advance the photographic plate. Each micrometer screw carries a long spiral gear and, by a system of smaller gears and shafts, all three micrometer screws are geared together to move equally and simultaneously when the large knurled head at $D$ is turned. The shaft upon which $d$ is mounted carries a graduated circle for reading fractional turns of the micrometer screws. An index ring also is carried on the same spindle and a springactuated detent engaging in the equispaced indentations enables one to obtain readily the fractional turns required when advancing the photographic plate between exposures. A Veeder counter at $e$ indicates the complete turns of the micrometer screws. The member that carries the plate is held tightly against the three micrometer screws by means of three spiral springs in the three cylindrical spring boxes that can be seen near the three micrometer screws and this member is supported by the crossed rods at $f$ and a similar pair of rods on the other side.

\section{TEST CHARTS}

The test charts for use in the colli-

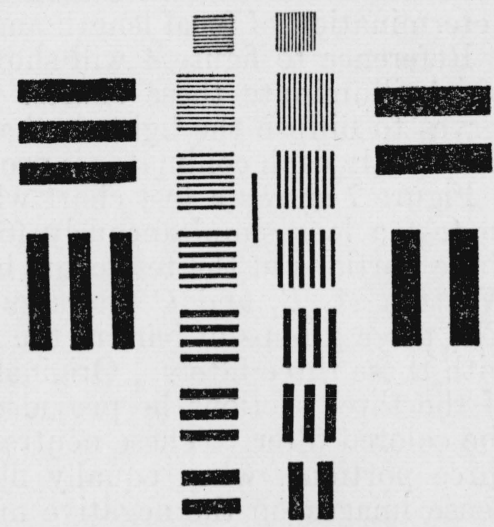

Figure 6.-Test chart for use with monochromatic light.

For lenses of a given iocal length, a series of test charts similar to this, one for each collimator, is provided. These charts are of such size that the number of lines to the millimeter, as recorded on the test plate, form the approximately geometric series $3.5,5,7,10,14,20$, 28,40 , and 56 . The central vertical line is the fiducial mark to which measurements are

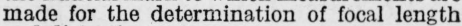
and distortion.

mators are drawn to a large scale and then photographed to the desired size upon backed process plates. Most of the lenses tested range in focal length from 125 to $250 \mathrm{~mm}$. The focal lengths of the collimator objectives are $1,000 \mathrm{~mm}$ and the chart, in most cases, is from 8 to 4 times as large in linear dimensions as the image finally recorded on the photographic plate in the course of a test. As a consequence of this reduction, the test charts produced on photographic plates have been found sufficiently sharp and free from grain to give satisfactory performance.

For testing a lens with monochromatic light the test chart shown in figure 6 has been found satisfactory. The production of a set of these charts is more complicated than might at first appear. If the test charts in all the collimators are identical in size it will be found that the images recorded on the negative at different distances from the axis will not be of the same size. If $\theta$ represents the angular 
distance of the image from the center of the field, the vertical dimensions of the images at different distances from the axis will vary inversely as $\cos \theta$ and the horizontal dimensions inversely as $\cos ^{2} \theta$. Furthermore, when lenses of different focal lengths are to be tested, it is desirable to have sets for each focal length to such scale that the patterns on the negatives will be of the same size for all focal lengths. This greatly facilitates a comparison of the definition of image yielded by the different lenses. Consequently, it has been found desirable to make the test charts in focal-length sets of seven, one for each collimator, with the vertical and horizontal dimensions varying according to the ratios $\cos \theta$ and $\cos ^{2} \theta$ in order that the seven images on a negative may be of the same size. The set of charts for lenses of a given focal length is so made that the lines will be spaced 3.5, $5,7,10,14,20,28,40$, and 56 to the millimeter on the test negative.

The vertical bar in the center of the pattern serves as a fiducial mark for the measurements on the negative that are required for the determination of focal length and distortion.

Reference to figure 4 will show the incandescent lamps (60 watts) which illuminate these charts. A single thickness of tracing cloth serves to diffuse the light so that the chart is uniformly illuminated. Commonly each collimator is provided with a K3 gelatine filter.

Figure 7 shows a test chart which has been used when it is desired to test a lens simultaneously for light of three wave lengths. The three portions of the test chart lettered $A, B$, and $C$ are covered with Wratten $A, B$, and $C$ filters such as are used in three-color work. The three groups of bars in the center are also covered, respectively, with these three filters. Originally it was the intention that each one of the three sections be provided with a neutral filter in addition to the colored filter. These neutral filters were to be so chosen that the three portions, when equally illuminated, would register as equally dense images on the negative made with the lens to be tested. Although such a balancing of the neutral filters can be obtained for a given box of panchromatic plates, it was soon discovered that the spectral sensitivity may vary so greatly with plates from different lots of emulsion that a readjustment of the filters would be desirable for each variation. To obviate this difficulty the neutral filters were removed and compensations secured by the sectored wheels shown in figure 4. Each sector disk is provided with three apertures which can be varied independently in angular width. The three apertures, instead of being left clear, are covered respectively with $A, B$, and $C$ gelatine filters. Only the sector aperture covered with the $A$ filter transmits light which is also transmitted by the $A$ portion of the chart, and analogous statements are valid for the $B$ and $C$ parts of the chart. Consequently, the light transmitted by the three parts of the chart can be varied independently by the three apertures in the single sectored disk. This makes it a simple matter to adjust the three parts of the chart to register on the negative with the same amount of blackening. When investigating the chromatic aberrations as indicated by a negative obtained by this test it is necessary to make suitable allowance for the chromatic aberrations of the collimator objectives. 


\section{ADJUSTMENT OF INSTRUMENT}

Four major adjustments must be correctly made in order that the results obtained may be satisfactory. The collimators must be focused so that the emergent rays are parallel; the angles between the axes of the collimators must have the desired values; the camera back
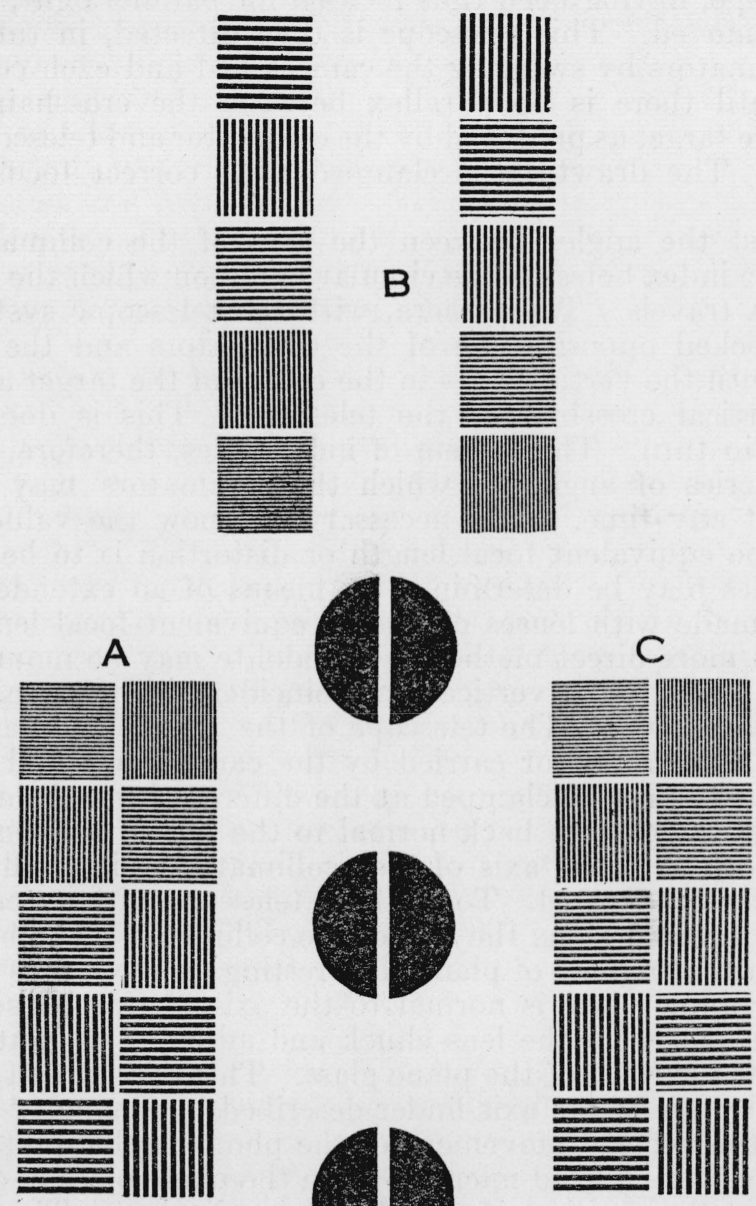

Figure 7.-Chart for tests of chromatic aberration.

The parts of the chart marked $A, B$, and $C$ are covered, respectively with Eastman's $A, B$, and $C$ filters. The circular disks in the center are similarly covered with the three different filters. The vertical marks in the disks serve as the fiducial marks for the determination of focal length and distortion for the different colors.

must be normal to the axis of the lens; and the plate must be translated in its own plane when it is shifted to present a fresh portion of its surface for each exposure.

To focus the collimators a telescope objective having a focal length of approximately $800 \mathrm{~mm}$ is placed in the chuck that ordinarily holds the lens to be tested. The carriage that carries the plateholder is 
removed and a Gaussian eyepiece with crosshairs is mounted on the carriage that ordinarily carries the microscope. The eyepiece and telescope objective form a telescopic system. A silvered optical plane is placed in front of the telescope objective and, by means of the Gaussian eyepiece, the system is focused by autocollimation until the image of the crosshairs is superposed upon the crosshairs without parallax. The telescope, having been thus focused for parallel light, the optical plane is removed. This telescope is then directed, in turn, at each of the collimators by swinging the camera bed and each collimator is focused until there is no parallax between the crosshairs and the image of the target as produced ky the collimator and telescope systems combined. The drawtube is clamped after correct focus has been obtained.

To adjust the angles between the axes of the collimators use is made of the index holes on the circular arc upon which the rear end of the camera travels. The camera, with the telescopic system still in place, is locked opposite one of the collimators and the collimator adjusted until the vertical bars in the center of the target are bisected by the vertical crosshair of the telescope. This is done for each collimator in turn. The system of index holes, therefore, provides a standard series of angles to which the collimators may be readily adjusted at any time. It is necessary to know the values of these angles if the equivalent focal length or distortion is to be measured. These angles may be determined by means of an extended series of exposures made with lenses of known equivalent focal length. In a second and more direct method, a theodolite may be mounted above the camera bed with its vertical axis coincident with that about which the camera revolves. The telescope of the theodolite may be autocollimated upon a mirror carried by the camera bed and the angles measured as the bed is clamped at the different index holes.

To adjust the camera back normal to the axis of the lens it is first adjusted normal to the axis of that collimator which will be coaxial with the lens to be tested. To do this a telescope with autocollimating eyepiece is directed along the axis of the collimator. The back is then adjusted so that a piece of plane glass resting on the ledges that locate the photographic plate is normal to the axis of this telescope. The lens is then placed in the lens chuck and adjusted so that its axis is normal to the surface of the plane glass. This adjustment of the lens is effected by use of the axis finder described by Bennett. ${ }^{4}$

To test the vertical movement of the photographic plate it is only necessary to focus a fixed microscope on the plane piece of glass which still occupies the position of the photographic plate. The glass plate should remain in focus when the plate is racked up and down.

\section{OPERATION OF LENS-TESTING CAMERA}

After the instrument has been adjusted and the lens is properly aligned by means of the axis finder the exposures are made. If a new type of lens is to be tested the vignetting of the lens must first be measured. To do this the camera back is set at the best focus, as determined visually, and the apertures of the seven sectored disks are all set at the same opening. Without varying the focus a series of exposures are made with the duration of exposure increasing geo-

- BS Sci. Pap. 19, 587 (1924) S494. 
metrically throughout the series. A 4 by 10 plate, as previously stated, permits 19 exposures to be made. By noting the exposures in the different columns that yield the same density a measure of the vignetting of the lens is obtained.

Next, the apertures of the sectors, on the basis of this measurement, are so adjusted that a given length of exposure will give the same blackening of the image in all columns. A suitable index plate for the detent mechanism on the micrometer-screw focusing movement is then selected to give the proper advance of the plate between exposures. The amount of the advance desired depends upon the relative aperture at which the lens is to be tested. If the relative aperture is $\mathrm{f} / 4.5$ an advance not greater than $0.05 \mathrm{~mm}$ per exposure is selected. With 19 exposures to the plate a total range of $0.90 \mathrm{~mm}$ of focus is explored on a single negative. If the relative aperture is smaller the advance is increased because of the greater depth of focus, this depth varying as the reciprocal square of the relative aperture. Before making the exposure the initial position of the camera back is so chosen that the central exposure of the range occurs when the plate is in the position of best focus. If all steps have been correctly taken the final negative will have seven columns of images of equal density, thus facilitating the judgment of the resolving power for different portions of the field. A horizontal row of images near the center of the range will be in best focus, with the rows above and below decreasing in sharpness.

To test a complete camera it is only necessary to remove the lens chuck and camera back of the apparatus and mount the airplane camera on a slide on the camera bed with the entrance pupil of the lens approximately at the intersection of the collimator axes and with the axis of the lens coaxial with that of the extreme right or left collimator. It is preferable to make two exposures, one with the right collimator coaxial with the lens, the second with the left coaxial. By this procedure a single row of images is recorded for an entire diameter of the field.

\section{PHOTOGRAPHIC TECHNIQUE}

Eastman type $V-B$ spectroscopic plates are used. This emulsion is much too slow for airplane mapping, but the resolving power is very much greater than for the usual panchromatic plate. This is an advantage for a test of lenses as it gives the lens an opportunity to show better resolution than can be recorded when used in the field. This makes it probable that an indicated deficiency of a lens, as shown by our tests, arises from a limiting fault in the lens rather than in the photographic technique. The plates are developed in developer prepared according to Eastman's formula D19, and they are fixed in solution $F 5$.

\section{INTERPRETATION OF TEST NEGATIVES}

The arrangement of images on the resultant test negative is shown in figure 2. The negative is examined by means of a microscope to determine which row of exposures gives the best average definition across the entire field. After the most favorable row of images has been selected, the images in this row are carefully examined and the quality of definition is indicated by stating the number of lines per millimeter that is resolved at the different distances from the center 
of the field. For each image two values are given, one applying to lines perpendicular to a radius drawn from the center of the field, the other to lines parallel to the radius. These values are designated respectively as tangential and radial resolving powers. Figure 8 gives enlarged reproductions of the images at the distance of best focus for a lens which covers a very large field with excellent definition. The resolving powers that are read from the negative are given in table 1.

TABLE 1.-Resolving power of lens of figure 8

\begin{tabular}{|c|c|c|c|c|c|c|c|c|c|}
\hline \multirow[b]{3}{*}{$\begin{array}{l}\text { Tangential..- } \\
\text { Radial }\end{array}$} & \multicolumn{9}{|c|}{ Degrees } \\
\hline & 0 & 5 & 10 & 15 & 20 & 25 & 30 & 35 & 40 \\
\hline & $\begin{array}{l}56 \\
56\end{array}$ & $\begin{array}{l}56 \\
56\end{array}$ & $\begin{array}{l}40 \\
56\end{array}$ & $\begin{array}{l}28 \\
40\end{array}$ & $\begin{array}{l}20 \\
40\end{array}$ & $\begin{array}{l}28 \\
40\end{array}$ & $\begin{array}{l}14 \\
40\end{array}$ & $\begin{array}{l}14 \\
20\end{array}$ & 14 \\
\hline
\end{tabular}

a The resolution here is less than that corresponding to the coarsest pattern on the chart, namely, 3.5 lines to the millimeter.

For the series of reproductions in figure 8 the key diagram at the left indicates the number of lines to the millimeter in each pattern of the target.

After the best horizontal row of images has been selected one counts up to this row from the last exposure and, knowing how much the plate was advanced between each two exposures, and having measured the distance from the vertex of the last surface of the lens to the emulsion when in position for the final exposure, one readily determines the back focal length corresponding to the position of the plate that yielded the best definition. In determining the back focal length in this manner the precision is limited by the precision with which one can select a given horizontal row on the test negative as representing the best average definition. The back focal length is not a uniquely determined quantity but there is a range of values corresponding to the depth of focus. This range of values over which the definition appears to have no significant difference in quality arises from the limited resolving power of the lens, the presence of aberrations and the granular character of the photographic emulsion. The larger the relative aperture of the lens the less will be the depth of focus. When a lens is tested with the diaphragm set at $f / 4.5$ it is customary to advance the plate $0.05 \mathrm{~mm}$ between exposures, and there are usually at least three adjacent rows on the plate that present excellent images and differ from each other only slightly in average excellence of imagery. When a lens is tested at $\mathrm{f} / 11$ the movement of the plate between exposures is seldom less than $0.10 \mathrm{~mm}$. Consequently, the back focal length is usually determined with an uncertainty of the order of $\pm 0.05 \mathrm{~mm}$ and our reports, in such cases, make no estimate of the probable error other than the statement that it does not exceed $\pm 0.10 \mathrm{~mm}$. This uncertainty causes the user of the lens no difficulty because it arises from no defect in the testing or in the camera but rather from an inherent or essential lack of precision with which the back focal plane can be experimentally located.

After the back focal length has been determined for the row of best definition the distances from the vertical bar of the axial images to 


\begin{tabular}{|c|c|c|c|c|}
\hline 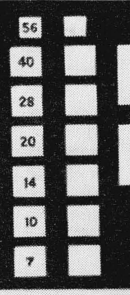 & 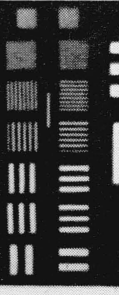 & 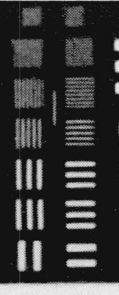 & $\begin{array}{l}0 \\
\text { dil } \\
\text { III } \\
\text { III } \\
\text { III }\end{array}$ & 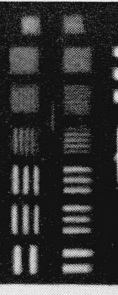 \\
\hline & $0^{\circ}$ & $5^{\circ}$ & $10^{\circ}$ & $15^{\circ}$ \\
\hline $\begin{array}{l} \\
\mathrm{v} \\
\mathrm{II} \equiv \\
\mathrm{II} \equiv \\
\mathrm{II} \equiv\end{array}$ & 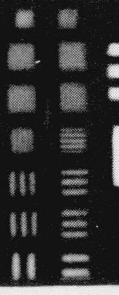 & 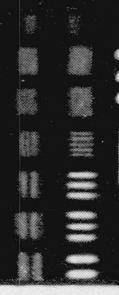 & 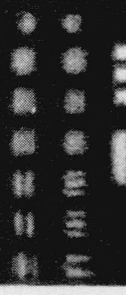 & \\
\hline $20^{\circ}$ & $25^{\circ}$ & $30^{\circ}$ & $35^{\circ}$ & $40^{\circ}$ \\
\hline
\end{tabular}

Figure 8.-Test of definition.

The standard test chart has been photographed at five-degree intervals from center to edge of the field and the resulting images enlarged approximately 12 diameters. The resolving on the negative corresponding to any element of the target. These reproductions demonstrate the excellent performance of a wide-angle lens, focal length $61 \frac{1}{2}$ inches, aperture $\mathrm{f} / 11$, specially designed for photogrammetric work although they
fail to record the finest detail of the original negative. The resolving powers, as read from the negative, are tabulated on page 458 . 
the corresponding bar in each of the other images in the same horizontal row is measured on the test negative. If there were no distortion, any one of these distances, divided by the tangent of the angle between the two corresponding collimators, would give the equivalent focal length. In general, because of the presence of distortion, the quotients obtained for the different angular distances will vary. In such cases it is customary to assume that the distortion for the images 5 and $10^{\circ}$ from the axis is negligible and obtain two determinations of the equivalent focal length from these two images. If this assumption is justifiable the two values of the equivalent focal length will agree closely and the mean is adopted as the equivalent focal length.

The probable error in the determination of the equivalent focal length depends upon the probable errors in the measurement of the angles between the collimators and the distances between the images on the test negatives. The angle between any two collimators can be determined with a probable error that does not exceed \pm 7 seconds and the lengths on the negative with a probable error that does not exceed $\pm 5 \mathrm{~m} \mu$. These values do not represent the probable errors obtained when a series of readings is made in rapid succession and averaged but may be termed effective probable errors and are made large to include the variations arising from inexact mounting of the lens in the lens chuck, secular changes of the apparatus and other causes that remain relatively constant during the progress of a given test but may change from test to test.

Applying these effective probable errors, the determination of equivalent focal length based upon the image $5^{\circ}$ from the axis has a probable error of approximately $\pm 0.1 \mathrm{~mm}$ and, for the $10^{\circ}$ image, the corresponding probable error is approximately half this. Consequently, the probable error in the determinations of the equivalent focal length does not exceed $\pm 0.1 \mathrm{~mm}$.

The distance from the central image to any image at an angular distance $\theta$ from the axis, minus the product of the equivalent focal length by $\tan \theta$, gives the distortion for the angular distance $\theta$ from the axis. This represents the actual displacement of the image from its distortion-free position, a positive value indicating that the image is displaced from the center of the picture outward as a result of the distortion. The determination of distortion, therefore, is based upon measurements precisely similar to those required for the determination of the equivalent focal length and subject to the same probable errors. The probable error in the determination of distortion is approximately proportional to the distance of the image point from the center of the field. Using the effective probable errors that have been given, the probable error for a point $115 \mathrm{~mm}$ from the center of the field (the center of one side of a 9-by 9-inch negative) does not exceed $0.02 \mathrm{~mm}$ for lenses of 150 - to $200-\mathrm{mm}$ focal length. In all of the foregoing measurements it is believed that the systematic errors of the testing camera fall within limits not exceeding the probable errors that have been given.

The equivalent focal length and distortion obtained by these procedures are the values as customarily defined for the purposes of geometrical optics. Actually the photogrammetist uses the equivalent focal length as a scale factor for the reduction of measurements made on his negatives. The presence of distortion indicates that the true scale factor varies from one part of the negative to another 
The value of the equivalent focal length, as referred to in the preceding paragraphs, is the scale factor for the central portion of the negative only. If the distortion is measured at $5^{\circ}$ intervals from the center to the edge of the field it may be possible to adopt a scale factor corresponding to some other portion of the negative and secure a better average fit over the entire field. This is an advantageous procedure with a lens having a large amount of distortion. Usually, however, the better quality airplane camera lenses that are now being submitted have so little distortion that this seems an unnecessary refinement. It is not uncommon to have the distortion at $30^{\circ}$ from the axis as small as $0.03 \mathrm{~mm}$ even when no such adjustment of the equivalent focal length has been made.

When a complete camera is received for test it has usually been focused and the lens and the guides locating the plane occupied by the film are adjusted and locked in the relative positions that they will have when the camera is used in the field. Consequently, the choice of back focal length has already been made and, if its value is required, it is only necessary to make a measurement, by means of a depth gage or other convenient instrument, of the distance from rear vertex of lens to the plane occupied by the photographic emulsion. ${ }^{5}$

As has been previously mentioned, an exposure with a camera yields a single row of images corresponding to the row of images giving the best average focus on a test negative made when testing a lens. These images are examined for a determination of resolving power and the distances between the vertical bars of the images are measured, after which the equivalent focal length and distortion are determined in the manner already described.

WAshington, January 11, 1937.

${ }^{5}$ If the camera contains a glass pressure plate between the photographic film and the lens this measured distance should be decreased by one-third the thickness of the pressure plate. 